\title{
Malignant Peripheral Nerve Sheath Tumor of the C2 Nerve Root: Case Report
}

\author{
Joshua D. Burks ${ }^{1}$ Robert G. Briggs ${ }^{1}$ Chad A. Glenn ${ }^{1}$ John C. Greenert ${ }^{2}$ Cordell M. Baker ${ }^{1}$ \\ Keren Bartal ${ }^{3}$ Greg A. Krempl ${ }^{3}$ Michael E. Sughrue ${ }^{1}$ \\ 1 Department of Neurosurgery, University of Oklahoma Health \\ Sciences Center, Oklahoma City, Oklahoma, United States \\ ${ }^{2}$ Department of Neurology, University of Oklahoma Health Sciences \\ Center, Oklahoma City, Oklahoma, United States

\begin{abstract}
Address for correspondence Michael E. Sughrue, MD, Department of Neurosurgery, University of Oklahoma Health Sciences Center, $1000 \mathrm{~N}$. Lincoln Blvd., Suite 4000, Oklahoma City, OK 73104, United States (e-mail: michael-sughrue@ouhsc.edu).
\end{abstract}

${ }^{3}$ Department of Otorhinolaryngology, University of Oklahoma Health Sciences Center, Oklahoma City, Oklahoma, United States

J Neurol Surg Rep 2017;78:e68-e70.

\begin{abstract}
Keywords

- malignant peripheral nerve sheath tumor

- skull base

- cervical nerve root

Here we present the case of a 36-year-old man who was found to have a symptomatic malignant neural sheath tumor growing from the $\mathrm{C} 2$ nerve root following a period of progressively worsening headaches. The patient was successfully treated with surgical resection resulting in resolution of cranial nerve deficits. Though uncommon, malignant peripheral nerve sheath tumor must be considered in the differential diagnosis of tumors involving the cervical nerve roots and carotid space.
\end{abstract}

\section{Introduction}

Malignant peripheral nerve sheath tumor (MPNST) is an uncommon tumor that can occur virtually anywhere in the body. ${ }^{1}$ These tumors proliferate rapidly and behave aggressively. Here we present the unusual case of a MPNST growing from the upper cervical nerve roots in an otherwise healthy young man.

\section{Case Report}

\section{History and Examination}

A 36-year-old man presented with hoarseness and rightsided tongue deviation following several months of worsening headaches. On magnetic resonance imaging (MRI), he was found to have a large, contrast-enhancing lesion in the right carotid space displacing the internal jugular vein laterally and the common carotid anteriorly, as shown in - Fig. 1. Imaging also demonstrated extension into the neural foramina at $\mathrm{C1}$ $\mathrm{C} 2$ and the hypoglossal canal. It was determined that the patient's symptoms were likely due to cranial nerve involvement by the mass. Given the rapid onset of symptoms, the patient's deficits were expected to worsen with time as the tumor continued to proliferate. Consequently, the patient elected to undergo surgical resection.

\section{Operation and Postoperative Course}

The tumor was resected through a combined far-lateral, suboccipital neck dissection to allow for good exposure of the ventrolateral brainstem and upper spinal cord. Incision lines are shown in - Fig. 2. The sternocleidomastoid and spinal accessory nerve were retracted to expose the great vessels, as shown in -Figs. $\mathbf{3 A}$ and $\mathbf{3 B}$. The tumor was then dissected free from the carotid sheath and vagus nerve. The lateral suboccipital space was exposed to the $\mathrm{C} 2$ spinal nerve's exit from the thecal sac, where this portion of the tumor was removed en bloc. The tumor was then dissected off the vertebral artery as in - Fig. $\mathbf{3 C}$ and was also dissected where it involved cranial nerves X and XII at the jugular foramen. Gross total resection was achieved around these structures with adequate margins, as shown in - Fig. 3D. Histopathology revealed components of MPNST. The patient was discharged 5 days postoperatively with partial posterior scalp numbness and an otherwise normal neurologic examination. $\mathrm{He}$ was subsequently treated with radiation therapy, and at his 6-month follow-up, he had no evidence of recurrence. received

August 19, 2016

accepted

December 21, 2016
DOI http://dx.doi.org/

$10.1055 / \mathrm{s}-0037-1598115$.

ISSN 2193-6358. (c) 2017 Georg Thieme Verlag KG Stuttgart · New York
License terms

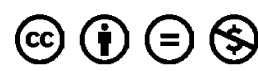




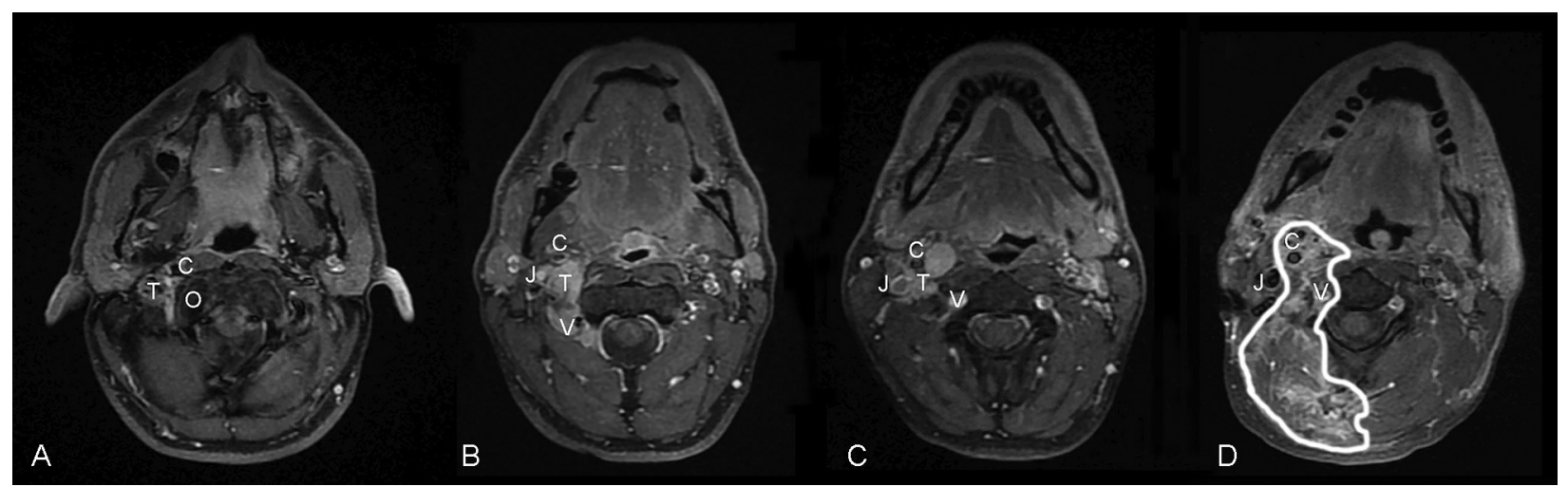

Fig. 1 (A) T1-weighted magnetic resonance imaging with gadolinium contrast showing a heterogeneously enhancing lesion on the right at the level of the jugular foramen, just lateral to the occipital condyle. (B) Tumor is seen involving the right carotid space, laterally displacing the internal jugular vein and anteriorly displacing the internal and external carotid arteries at the $C 2$ vertebral level. The tumor is enveloping the vertebral artery on the right side. (C) Tumor is visible coursing along the medial edge of the internal carotid artery at the C3 vertebral level. (D) Postoperative T1-weighted image with contrast showing mild edema and inflammation around the area of resection (outlined), with no focal enhancement. C, Internal carotid artery; J, internal jugular vein; T, tumor; O, occipital condyle; $\mathrm{V}$, vertebral artery.

\section{Discussion}

MPNST is a rare entity defined as a malignant tumor arising from a peripheral nerve or having nerve sheath differentiation. ${ }^{1}$ These tumors are most often found in the extremities and trunk, though approximately $20 \%$ occur in the head and neck. ${ }^{1}$ Making the diagnosis can be difficult, as MPNST histopathology has shown marked variability with possible divergent differentiation (e.g., rhabdomyosarcomatous differentiation consistent with our patient's tumor). ${ }^{2}$ Furthermore, MRI cannot distinguish between malignant and benign nerve sheath tumors. ${ }^{3}$

The nature of MPNST is highly aggressive and carries a poor prognosis. ${ }^{4}$ Current 5 -year survival rates are reported from 44 to $60 \%$ for patients with any MPNST. ${ }^{1,3}$ The mainstay of treatment is maximal surgical resection with adjuvant radiotherapy for local tumor control. ${ }^{1,4,5}$ Some have shown that surgery and radiotherapy do not confer any survival

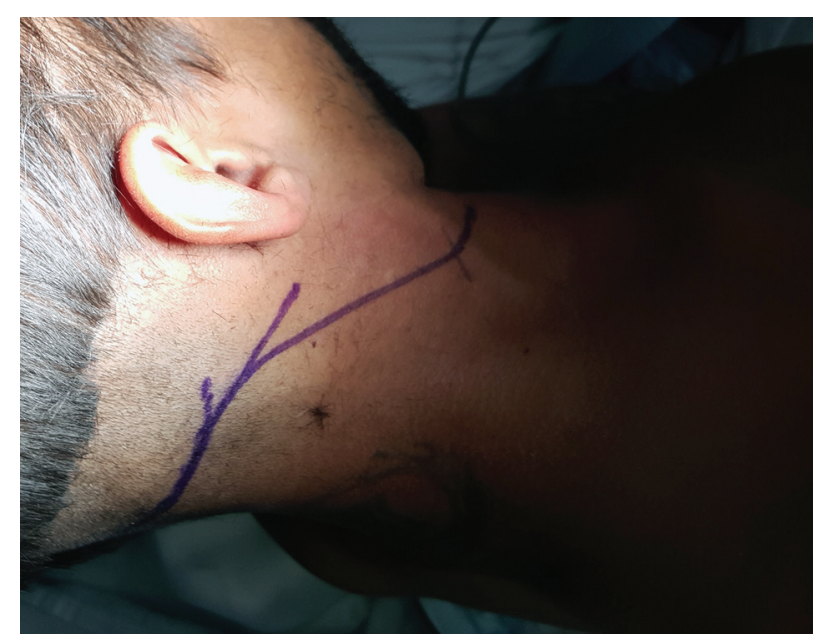

Fig. 2 Intraoperative photograph showing incision lines in combined far-lateral, suboccipital lateral neck dissection. benefit, but do delay time to local recurrence. ${ }^{3}$ Others have shown that lack of radiation predicts decreased diseasespecific survival. ${ }^{4}$ Typically, chemotherapy is not used to treat these tumors, ${ }^{1}$ although some have questioned this view with more recent reports detailing the improved survival benefit in patients with MPNST treated with doxorubicin and ifosfamide. ${ }^{6}$ Given their limited sample size, however, additional research into the role of chemotherapy in treating MPNST is necessary. Fitting with standard practices, our patient received adjuvant radiation following surgery.

To our knowledge, this case is the first report of MPNST occurring in the upper cervical nerve roots and hypoglossal nerve. Previous reports of MPNST occurring within the cervical spine and brainstem include one case of a 23-year-old woman who was diagnosed 17 months following resection of a schwannoma. The schwannoma was initially resected from the C7-T1 cord level, followed by posterior fusion of C3-T3 and sacrifice of the $\mathrm{C} 8$ nerve root. The tumor later recurred as low-grade MPNST at the C3-T3 cord level. ${ }^{7}$ In another report, a 30-year-old woman was found to have MPNST involving the sixth cranial nerve. The tumor was resected through an extended left retrosigmoid craniotomy to access the anterior cerebellopontine angle and brainstem. ${ }^{8}$ At 1-year follow-up, the patient was neurologically intact with a small amount of residual tumor.

In addition to sporadic MPNST, malignant nerve sheath tumors classically occur as a result of malignant transformation of an existing plexiform neurofibroma in the setting of neurofibromatosis type 1 (NF-1). ${ }^{9}$ Patients with NF-1 carry a $10 \%$ lifetime risk of such a transformation ${ }^{9}$; however, $36 \%$ of MPNST cases are thought to occur in patients with NF-1 without a previous neurofibroma diagnosis. ${ }^{10}$ Given that our patient did not have additional signs or symptoms of NF-1, including other neurocutaneous disease or a family history of NF-1, we felt his malignancy was likely sporadic.

Though uncommon, MPNST must be considered in the differential diagnosis of tumors involving the cervical nerve 


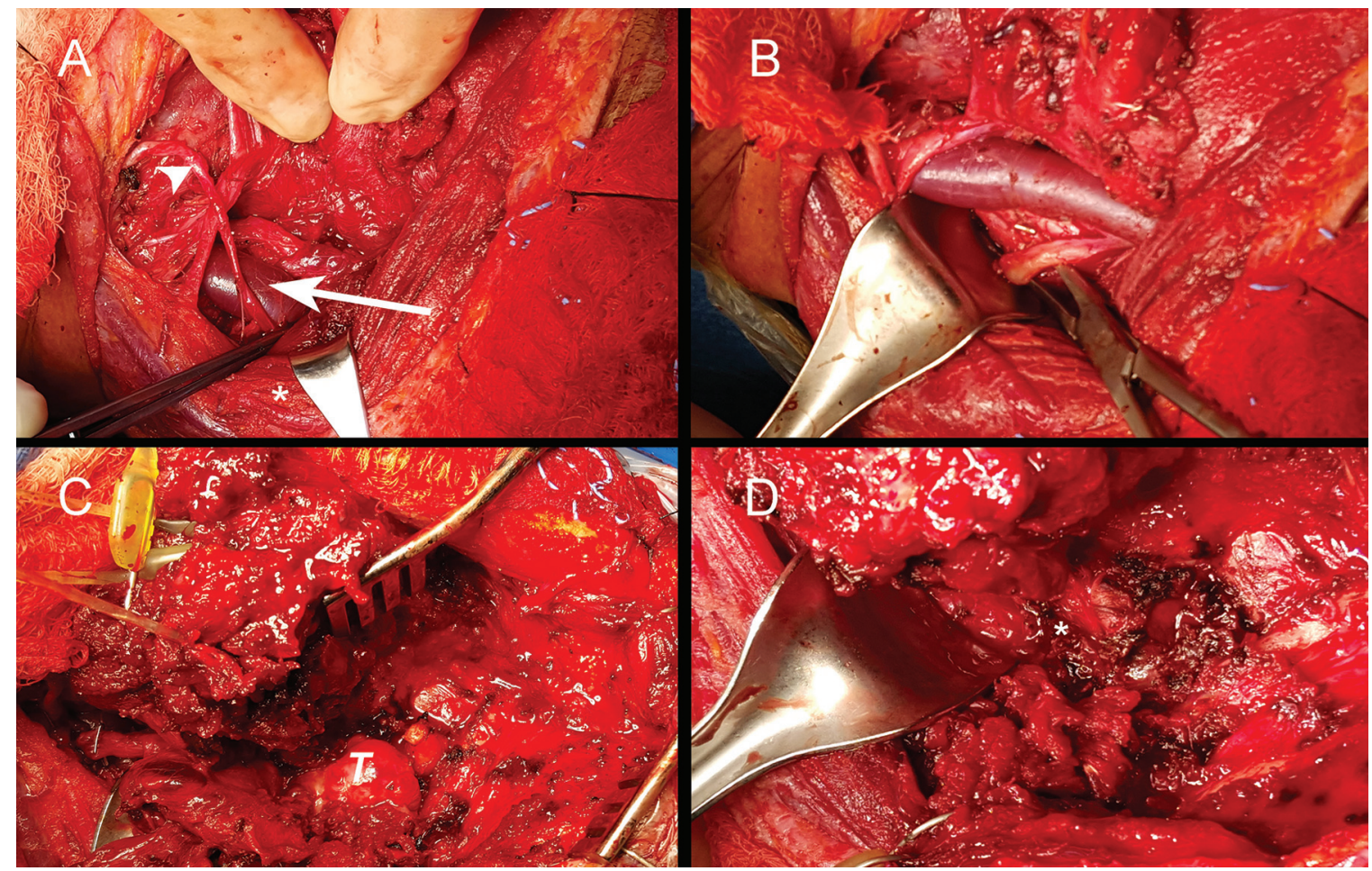

Fig. 3 (A) The sternocleidomastoid $\left(^{*}\right)$ retracted to expose the common carotid artery (arrow) and dissection of the spinal accessory nerve (arrowhead). (B) The spinal accessory nerve and sternocleidomastoid are retracted to expose the carotid sheath. (C) Retraction of the carotid and deeper dissection revealing part of tumor mass $(T)$. (D) Gross total resection was achieved. Location of the vertebral artery is indicated by $\left(^{*}\right)$.

roots and the carotid space even without a history of neurofibromatosis.

\section{Disclosure}

The authors report no conflict of interest concerning the materials or methods used in this study or the findings specified in this report.

\section{Funding}

None.

\section{Acknowledgments}

None.

\section{References}

1 Stucky CC, Johnson KN, Gray RJ, et al. Malignant peripheral nerve sheath tumors (MPNST): the Mayo Clinic experience. Ann Surg Oncol 2012;19(03):878-885

2 Thway K, Fisher C. Malignant peripheral nerve sheath tumor: pathology and genetics. Ann Diagn Pathol 2014;18(02):109-116
3 Gachiani J, Kim D, Nelson A, Kline D. Surgical management of malignant peripheral nerve sheath tumors. Neurosurg Focus 2007;22(06):E13

4 Anghileri M, Miceli R, Fiore M, et al. Malignant peripheral nerve sheath tumors: prognostic factors and survival in a series of patients treated at a single institution. Cancer 2006;107(05): 1065-1074

5 Wong WW, Hirose T, Scheithauer BW, Schild SE, Gunderson LL. Malignant peripheral nerve sheath tumor: analysis of treatment outcome. Int J Radiat Oncol Biol Phys 1998;42(02):351-360

6 Moretti VM, Crawford EA, Staddon AP, Lackman RD, Ogilvie CM. Early outcomes for malignant peripheral nerve sheath tumor treated with chemotherapy. Am J Clin Oncol 2011;34(04): 417-421

7 Winslow N, Abode-Iyamah K, Kirby P, Smith M, Reddy C. Malignant peripheral nerve sheath tumor arising in the setting of cervical nerve root schwannomas. J Clin Neurosci 2015;22(10):1696-1699

8 Voorhies J, Hattab EM, Cohen-Gadol AA. Malignant peripheral nerve sheath tumor of the abducens nerve and a review of the literature. World Neurosurg 2013;80(05):654.e1-654.e8

9 Mautner VF, Friedrich RE, von Deimling A, et al. Malignant peripheral nerve sheath tumours in neurofibromatosis type 1: MRI supports the diagnosis of malignant plexiform neurofibroma. Neuroradiology 2003;45(09):618-625

10 King AA, Debaun MR, Riccardi VM, Gutmann DH. Malignant peripheral nerve sheath tumors in neurofibromatosis 1 . Am J Med Genet 2000;93(05):388-392 